\title{
Perspectives on flood forecast-based early action and opportunities for Earth observations
}

\author{
Claire Nauman, ${ }^{\text {a,b, } * \text { Eric Anderson } \odot, ~}{ }^{\text {b,c }}$ Erin Coughlan de Perez $\odot, \stackrel{\text { d,e }}{\text { e }}$

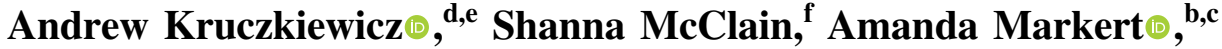 \\ Robert Griffin $\odot,{ }^{a, b}$ and Pablo Suarez ${ }^{\text {d,g }}$ \\ ${ }^{a}$ The University of Alabama in Huntsville, Department of Atmospheric and Earth Science, \\ Huntsville, Alabama, United States \\ ${ }^{\mathrm{b}}$ NASA/SERVIR Science Coordination Office, NASA Marshall Space Flight Center, Huntsville, \\ Alabama, United States \\ ${ }^{\mathrm{c}}$ The University of Alabama in Huntsville, Earth System Science Center, Huntsville, Alabama, \\ United States \\ ${ }^{\mathrm{d}}$ Red Cross Red Crescent Climate Centre, The Hague, Netherlands \\ ${ }^{\mathrm{e}}$ Columbia University, International Research Institute for Climate and Society, \\ The Earth Institute, New York, United States \\ ${ }^{\mathrm{f}}$ NASA Headquarters, Washington, DC, United States \\ ${ }^{g}$ Boston University, Pardee Center for the Study of the Longer-Range Future, Boston, \\ Massachusetts, United States
}

\begin{abstract}
This paper seeks to identify opportunities to integrate Earth observations (EO) into flood forecast-based early action and propose future directions for research and collaboration between $\mathrm{EO}$ and humanitarian communities. Forecast-based early action $(\mathrm{FbA})$ is an approach to shift disaster response toward anticipation to mitigate impacts to at-risk communities; however, timely and accurate information is needed in the development of data-based triggers and thresholds for action. Therefore, this paper considers the readiness of a wide range of EO for flood monitoring and forecasting in the design, operations, and evaluation phases of $\mathrm{FbA}$. The most significant opportunities for $\mathrm{EO}$ to inform $\mathrm{FbA}$ efforts lie in the design and evaluation phases, as EO can aid in the development of impact-based triggers. The EO products most readily applicable include precipitation, streamflow estimates, and exposure mapping, and those requiring the greatest amount of further research include vulnerability and impact assessments. This paper identifies collaboration opportunities for the EO and humanitarian communities to create tailored products, such as overlays combining flood extents with exposure maps. Such collaboration opportunities can be fostered by open data sharing, data verification efforts, and incentives for supporting boundary organizations capable of enabling the use of EO for FbA. (c) The Authors. Published by SPIE under a Creative Commons Attribution 4.0 Unported License. Distribution or reproduction of this work in whole or in part requires full attribution of the original publication, including its DOI. [DOI: 10.1117/1.JRS.15.032002]
\end{abstract}

Keywords: forecast-based early action; impact-based forecasting; flood forecast; Earth observations; satellite remote sensing; disaster management.

Paper 200787SS received Nov. 11, 2020; accepted for publication Dec. 30, 2020; published online Feb. 23, 2021.

\section{Introduction}

Floods cause significant damage and loss of lives worldwide, more so than any other type of natural disaster. ${ }^{1}$ In an effort to minimize flood impact and the impact of all disasters, international bodies have come together to set goals and priorities for disaster risk reduction, as presented in the Hyogo Framework for Action and its successor, the Sendai Framework for Disaster Risk Reduction. ${ }^{2,3}$ The goals outlined in these frameworks have encouraged the development of risk reduction strategies by a wide array of sectors. One such approach is the humanitarian community's forecast-based early action $(\mathrm{FbA})$, which endeavors one to enable action

*Address all correspondence to Claire Nauman, cmn0009@uah.edu 
based on forecasts of extreme events. Forecast-based Financing for early action is gaining momentum as an approach to manage changing climate risks, including through United Nations Framework Convention on Climate Change (UNFCCC)-related processes and the Green Climate Fund. ${ }^{4}$

In recent years, many organizations have developed and strengthened $\mathrm{FbA}$ efforts for a variety of hazards, with flooding being one of the most common. ${ }^{5}$ Based on these initiatives, challenges in linking flood forecasts to action include bridging the gap between forecasts of physical phenomena and impact on lives and livelihoods, tailoring existing forecasts to local contexts and needs, and sharing information that is relevant and translatable across disciplines. Given these challenges and the promising growth of the field, we see an opportunity for the EO community to learn from and contribute to $\mathrm{FbA}$ efforts aimed at flood risk reduction.

In this paper, we provide a brief introduction to $\mathrm{FbA}$, describe the readiness of Earth observations (EO) to inform flood $\mathrm{FbA}$, and discuss challenges, opportunities, and recommendations for the EO community to better serve the needs of humanitarian programs implementing FbA.

\section{Context}

For the EO community to serve the needs of the FbA community, a general understanding of the FbA concept is needed. In this section, we provide an overview of the FbA framework, locations where $\mathrm{FbA}$ is currently implemented, and the core FbA concepts EO scientists should know.

\subsection{Introduction to the Forecast-Based Early Action Concept}

Despite efforts to shift focus toward risk reduction, in the last 20 years, $\sim 12 \%$ of funding for disasters has been spent on reducing disaster risk, with the remaining $88 \%$ spent on emergency response, reconstruction, and rehabilitation. ${ }^{6}$ With such an imbalance in funding, the investments in risk reduction strategies must be highly effective. Studies have found that taking preventative action to avoid disaster losses can provide significant return on investment. ${ }^{7}$ Hallegatte $^{8}$ describes how investing in early warning systems (EWS) can yield returns via avoided losses and increased economic production in weather-sensitive sectors. Another study estimated that flood early action could save US\$34 per dollar invested in flood prone districts in Nepal. ${ }^{9}$ Statistics such as these have strengthened financial support from governments and donor agencies for the development of EWS, with the hopes that these systems might make it possible for people to act before an extreme event occurs, saving lives, and reducing impact. However, oftentimes, action is not taken in response to warnings from such EWS, ${ }^{10,11}$ and an early warning has no effect without early action. ${ }^{12} \mathrm{FbA}$ systems are meant to change this, enabling people to take pre-emptive action based on a forecast, even under conditions of uncertainty. ${ }^{13,14}$

$\mathrm{FbA}$ is an approach utilized in humanitarian communities to trigger early action when a severe weather or climate forecast reflects a high likelihood of critical impact to lives and livelihoods in a targeted area. The intention is to anticipate disasters and mitigate their impact to reduce human suffering and loss. FbA combines meteorological forecast information with risk analysis to identify where and when early actions should be implemented. To identify the spatial and temporal areas of action, FbA relies on a complex system of variables to prioritize risk and impact.

In many FbA systems, anticipatory or early action protocols detail the roles and responsibilities for action. These protocols take into account the forecast probability, the type of hazard, the magnitude of the event predicted, the early actions that may be taken, the cost and effects associated with the action or inaction, and the organizations required to facilitate such activities. ${ }^{13}$ Each component has associated questions and challenges to consider. ${ }^{15}$ For example, how should one determine critical magnitudes of an extreme event that should trigger action? What type of impacts might different magnitudes cause? Once that magnitude or danger level is identified, what is the appropriate level of probability for a certain action to be justified? Does the probability of the forecast reflect reality, or does the forecast predict higher or lower probabilities than actually occur?

As interest in the concept of $\mathrm{FbA}$ grows, so does the number of $\mathrm{FbA}$ programs and actors involved. Figure 1 shows the locations of $\mathrm{FbA}$ programs implemented by the International 


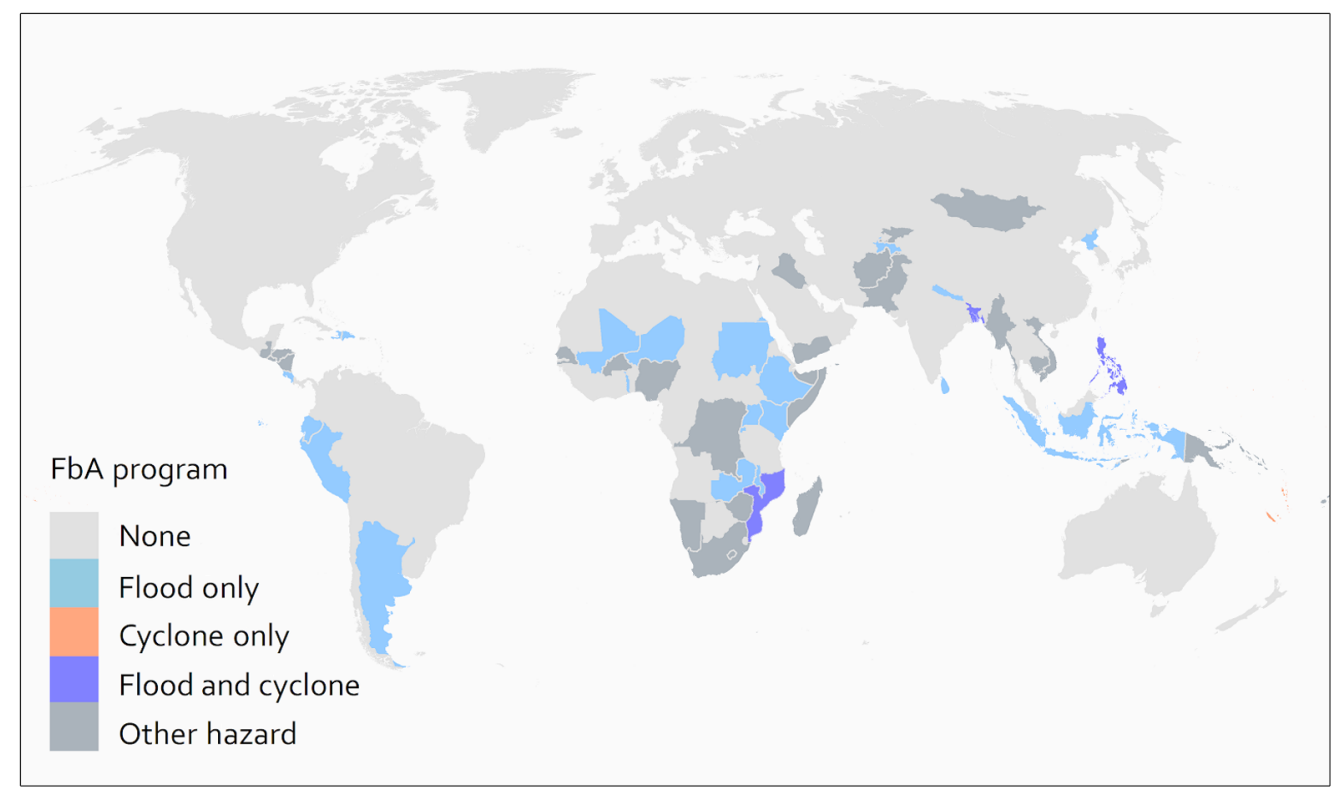

Fig. 1 Countries with FbA programs and their associated hazard focus implemented by the International Federation of Red Cross and Red Crescent Societies, Start Network, World Food Program, and Food and Agriculture Organization. ${ }^{16,17}$

Federation of Red Cross and Red Crescent Societies, Start Network, World Food Program, and Food and Agriculture Organization. ${ }^{16,17}$ Most of these programs focus on droughts or floods, with a few other hazard types interspersed, such as cold waves in Peru, volcanoes in Ecuador, dzud in Mongolia, or heat waves in Vietnam. Of the 53 countries with active FbA programs, 19 have a flood or cyclone focus. Many of these flood FbA programs use probabilistic or deterministic forecasts, whereas others use real-time monitoring data, historical data, or a combination of forecasts and real-time data. ${ }^{5}$

\subsection{Determining Triggers}

Most FbA programs take one of two main approaches to determine when to act: pre-defined triggers or real-time forecast-informed decision-making. ${ }^{5} \mathrm{We}$ focus on pre-defined triggers here, because they represent a novel aspect of $\mathrm{FbA}$, distinguishing FbA from typical EWS. Triggers are defined by the danger level or magnitude of a forecasted event (e.g., $100 \mathrm{~mm}$ of rain over $24 \mathrm{~h}$ ) and forecast probability (e.g., $80 \%$ chance of the event occurring). In more recent implementations of $\mathrm{FbA}$, triggers are being defined in terms of impact, rather than hazard, following guidelines proposed for impact-based forecasting. ${ }^{18,19}$ For example, an impact-based trigger would instigate action if more than $30 \%$ of houses in a community are forecasted to flood, which could happen from several different hazards, such as storm surge or rainfall-induced flooding. A trigger determined solely based on a hazard (e.g., a given river height) is defined by relating those historic river heights to their documented impacts but does not include potential impacts of related hazards.

Several methods exist to design triggers for FbA systems. ${ }^{11,14,15,20-22}$ Several approaches draw on the value of information arguments, which seek to move beyond using typical forecast verification metrics to quantify skill, toward assigning economic value to observations and forecasts. ${ }^{23-28}$ To assess the financial costs and benefits of any potential trigger, designers build contingency tables such as the one shown in Table 1, building on the choice molecule approach described by Suarez et al. ${ }^{29}$ Together, the false alarm ratio (FAR) [FAR $=$ false positives/(true positives + false positives)] and the total number of times an action will be triggered will determine the expected cost of the FbA program over time. The number of expected "worthy actions" directly conveys $\mathrm{FbA}$ program benefit via avoided losses. "actions in vain" may pose reputational risks but not all false positives may be considered total losses-some actions in vain may 
Nauman et al.: Perspectives on flood forecast-based early action and opportunities...

Table $1 \mathrm{FbA}$ outcome scenarios.

\begin{tabular}{lcc}
\hline \hline & \multicolumn{1}{c}{ Extreme event } & No extreme event \\
\hline Action & Worthy action (true positive) & Action in vain (false positive) \\
No action & Fail to act (false negative) & Worthy inaction (true negative) \\
\hline \hline
\end{tabular}

Note: adapted from Lopez. ${ }^{22}$

have secondary benefits (e.g., awareness campaigns on hygiene may help prevent the spread of disease; first aid kits can serve any type of unexpected accident).

\subsection{FbA Phases}

This paper considers three phases of FbA programs: design, operations, and evaluation. The design phase includes the development of an impact-based trigger and results in protocols outlining anticipatory or early actions. A key element of the design phase is to explore questions around both climate risk and vulnerability. For example, there is a need to explore who is vulnerable to the flood hazard and where they are located, to consider the skill of available forecasts, and to identify the probability of occurrence of flood events of different magnitudes (linked to the so-called return period, a problematic term for risk communication instances-especially given climate change and physical interventions in river basins). The operations phase is when realtime monitoring and forecasting occur, and early actions take place according to protocol. The evaluation phase includes steps to monitor and track indicators to learn from and evaluate whether the program met its objectives to reduce overall flood impact in cost-effective ways [akin to Monitoring, Evaluation, and Learning (MEL) in development parlance]. Evaluation can occur during and after the design and operations phase.

\section{Readiness of Earth Observation to Inform Flood Forecast-based Action}

The next sections consider the abilities and limitations of EO in all three phases of FbA. Further, the ability of EO to characterize physical hazard versus exposure, vulnerability, and impact of floods is also examined. Many thorough reviews exist on methods and uncertainties of flood modeling, the integration of EO into flood modeling, and the state of operational use of flood models (e.g., Refs. 30-34). The role of EO builds on an understanding that flood forecasts can be generated from hydrologic and/or hydraulic models that use combinations of in situ, remotely sensed, and modeled inputs. These inputs can be static (e.g., elevation, land cover, and river channel morphology) and dynamic (e.g., precipitation, evapotranspiration, soil moisture, snow cover, and snow water equivalent). Flood monitoring with EO often refers to historical or near real-time observation of flood extent with both active and passive sensors. To measure or forecast flood exposure, vulnerability, and impact, EO data and techniques must be combined with dynamic socioeconomic data and further multidisciplinary perspectives. This poses nearly insurmountable challenges for accuracy in an operational sense, but careful incorporation of EO in the design phase may position the satellite remote sensing community to more meaningfully inform impact-based triggers.

\subsection{Current Examples of EO in the Operational Phase of FbA Programs}

The main variables currently used to trigger action for floods are forecasted river height and streamflow. EO-based precipitation observations and numerical weather prediction (NWP) products are often used as inputs to hydrologic models that provide streamflow or river height-based triggers (e.g., Refs. 18 and 35), as evidenced in Bangladesh, Zambia, and Peru, among other countries. ${ }^{36}$ In this way, EOs are also the basis of NWP-derived triggers for cyclones (e.g., wind speed) in the Philippines and El Niño-related hazards (e.g., temperature and precipitation) in 
Peru. ${ }^{37,38}$ Early action protocols such as those in Bangladesh and Peru are based on global and national flood forecasting systems. Often, global systems with longer outlooks (e.g., the Global Flood Awareness System) trigger a first phase of initial preparedness actions and are followed by national forecasts with shorter outlooks (e.g., Bangladesh Flood Forecasting and Warning Center) that can trigger a second phase of actions like evacuation and cash assistance. ${ }^{36,39}$

We should point out that even the lowest latency, near-real time EO-based flood monitoring products, by definition, provide less lead time for early actions, especially if consulted without any additional historical context related to expected impact. These flood monitoring products might be most useful in the anticipation of secondary flood impacts, such as disease outbreaks. Therefore, the design and evaluation phases are reviewed to uncover EO's greatest untapped potential for FbA.

\subsection{Future of EO in Designing and Evaluating FbA Programs}

For EO science and data to more meaningfully serve FbA goals of reducing costs of responding to floods and reducing flood impacts, the EO community must play a stronger role in the design phase. Table 2 reflects the readiness of EO inputs in the design and evaluation phases. This was conducted by weighing scientific and organizational factors in assigning readiness and considering the NASA Application Readiness Level (ARL) metric. ${ }^{40}$ Readiness factors include the ability of EO science and technology to characterize the specific flood-related phenomenon, and the extent to which EO has been used for basic research (low ARL) versus approved for decision-making environments (high ARL). In Table 2, a key is provided for interpreting the readiness ratings shown in Table 2 . To aid discussion, the flood-related variables are ordered from fundamental (i.e., precipitation and soil moisture), intermediate (i.e., river height, streamflow, flood extent, and depth), to complex (i.e., exposure, vulnerability, and impact).

Also noted are the differences between forecasting and monitoring variables that $\mathrm{EO}$ can capture. Monitoring variables such as observed flood extent and depth can inform the design and evaluation phases, but it is unclear to what extent EO-based monitoring adds value to the operational phase of $\mathrm{FbA}$, especially given wide ranges of flood duration and magnitude of impact. Generally, only forecast variables have roles in the operations phase. One notable exception may arise if a monitoring variable that characterizes antecedent conditions (e.g., soil moisture) is determined to add value to predicting flood impact when coupled with other forecast data.

The most significant opportunities for $\mathrm{EO}$ to enhance $\mathrm{FbA}$ programs and to gain applications experience through $\mathrm{FbA}$ lie in the design phase. To develop impact-based triggers, research is ongoing to determine the extent to which fundamental variables such as precipitation and soil moisture can play a role, whether used independently or as combined indices to serve as proxies or precursory signals of flood impact (e.g., Refs. 20 and 41-45). River height and streamflow (e.g., Refs. 46-50) are the most common trigger variables used in flood FbA programs, but by themselves do not describe flood impact. Intermediate variables such as flood extent and depth come closer and are traditionally derived through simulations of hydrologic and hydraulic models. Other studies demonstrate that EO can be used to construct historic catalogs that relate historic streamflow or river height to resulting flood extent and onset date (e.g., Refs. 41 and 51), depth (e.g., Ref. 52), and exposure (e.g., Refs. 53-56). To determine triggers based on impact and to operationalize impact-based forecasts for early action, it may not be necessary to produce forecasts of depth, exposure, vulnerability, or impact. Rather, in the design phase, triggers can be defined based on the impact associated with more readily available flood variables (e.g., river height or streamflow). Again, depth, exposure, and vulnerability play critical roles in determining expected levels of flood impact, but these complex variables may not need to be forecasted in real time to define and trigger early actions to reduce impacts.

While the entire range of flood variables captured by EO is poised to support the design phase, the evaluation phase likely demands perspectives from the more complex variables. To be clear, the evaluation phase of $\mathrm{FbA}$ assesses whether the $\mathrm{FbA}$ program achieved its intended goals of reducing flood impacts using MEL tools, not the accuracy of a flood forecast. This is why the readiness of " $\mathrm{n} / \mathrm{a}$ " has been assigned to the fundamental and intermediate variables in the evaluation phase. Traditionally, program evaluations may involve expensive household and 
Table 2 Readiness of EO inputs for FbA.

(a) Relating EO readiness to calls for action

\begin{tabular}{lll}
\hline Symbol & $\begin{array}{l}\text { Readiness of } \\
\text { EO in FbA phase } \\
\text { (ARL range) }\end{array}$ & Interpreting EO for FbA Readiness as "calls to action" \\
\hline$*$ & Low (1 to 2) & $\begin{array}{l}\text { More multidisciplinary, fundamental, and applied research } \\
\text { must be funded, ideally by multiple agencies }\end{array}$ \\
Medium (3 to 5) & $\begin{array}{l}\text { Some fundamental research and significant applied } \\
\text { research are required }\end{array}$ \\
High (6 to 7) & $\begin{array}{l}\text { Some applied research remains; EO scientists and } \\
\text { humanitarian organizations should be poised to } \\
\text { co-develop better solutions }\end{array}$ \\
Very high (8 to 9) & $\begin{array}{l}\text { Connections may already exist; if not, these should } \\
\text { be ready to incorporate into early action protocols }\end{array}$ \\
\hline
\end{tabular}

(b) Readiness of EO inputs for flood phenomena by FbA phase

\begin{tabular}{|c|c|c|c|}
\hline FbA phase & $\begin{array}{l}\text { Flood-related } \\
\text { phenomena }\end{array}$ & EO inputs ${ }^{b}$ & Readiness \\
\hline \multirow{9}{*}{$\begin{array}{l}\text { DESIGN } \\
\text { Development } \\
\text { of impact-based } \\
\text { trigger }\end{array}$} & Precipitation & $\begin{array}{l}\text { Satellite precipitation products, quantitative } \\
\text { precipitation forecast }\end{array}$ & **** \\
\hline & Soil moisture & $\begin{array}{l}\text { All above inputs + typical variables in a Land } \\
\text { Surface Model (LSM) }\end{array}$ & ** \\
\hline & River height & $\begin{array}{l}\text { All above inputs + potentially including altimetry } \\
\text { and reservoir operations into hydrologic model }\end{array}$ & *** \\
\hline & Streamflow & All above inputs & 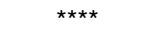 \\
\hline & Flood extent & All above inputs + optical and radar satellite imagery & $* \star *$ \\
\hline & Flood depth & All above inputs + digital elevation model (DEM) & *** \\
\hline & Exposure & $\begin{array}{l}\text { All above inputs }+ \text { nighttime lights, populated } \\
\text { areas/density, agricultural areas/crop type, } \\
\text { building footprints, and infrastructure }\end{array}$ & *** \\
\hline & Vulnerability & All above inputs + additional socioeconomic analysis & * \\
\hline & Impact & $\begin{array}{l}\text { All above inputs + additional socioeconomic } \\
\text { and cost analysis }\end{array}$ & * \\
\hline \multirow[t]{6}{*}{$\begin{array}{l}\text { EVALUATION } \\
\text { Program MEL }\end{array}$} & $\begin{array}{l}\text { Precipitation, } \\
\text { soil moisture, } \\
\text { river height, } \\
\text { and streamflow }\end{array}$ & & $\mathrm{n} / \mathrm{a}$ \\
\hline & Flood extent & Optical and radar satellite imagery & **** \\
\hline & Flood depth & All above inputs + DEM & *** \\
\hline & Exposure & $\begin{array}{l}\text { All above inputs + nighttime lights, populated } \\
\text { areas/density, agricultural areas/crop type, building } \\
\text { footprints, infrastructure }\end{array}$ & *** \\
\hline & Vulnerability & All above inputs + additional socioeconomic analysis & * \\
\hline & Impact & $\begin{array}{l}\text { All above inputs + additional socioeconomic and } \\
\text { cost analysis }\end{array}$ & * \\
\hline
\end{tabular}

abased on the ability of EO to characterize the phenomenon and EO's demonstrated current use, roughly mapped to NASA ARL

${ }^{b} E O$ inputs, whether direct inputs or derived from/with satellite inputs 
community surveys. EO-derived flood extent and depth estimates could add more extensive perspectives of $\mathrm{FbA}$ program areas. EO information could target locations for surveys or complement existing surveys. If the findings in the evaluation point to poorly performing triggers during operations, a more localized accuracy assessment of fundamental variables (i.e., a traditional, scientific validation exercise) might help diagnose failures or breakdowns in impact-based early actions. Ultimately, findings from programmatic evaluations should feedback into research and design, and hopefully improvements in operations. For instance, a monitored flood extent map during or immediately after a flood event may serve to adjust thresholds to better capture forecast flood impact. Annual redesigns may also benefit from the perspectives of EO. Lessons point to the potential value of EO to annually update maps, and resulting flood inundation forecasts, in regions with expected changes in vulnerability (e.g., vulnerable island populations).

\section{Further Serving Humanitarian Flood Early Action}

This section now considers a roadmap for collaboration. Researchers and practitioners in the EO community have a responsibility to demonstrate benefit to society; collaborating with the humanitarian community on $\mathrm{FbA}$ may be one way to do so. Some EO inputs are very mature, whereas others require further tailoring to be relevant to the different phases of FbA. This section reflects the challenges and opportunities for joint research and action between the EO and humanitarian communities, with the FbF research roadmap in mind. ${ }^{57}$

\subsection{Tailoring Forecasts to Humanitarian Needs}

The EO community can serve humanitarian needs in the $\mathrm{FbA}$ design phase by tailoring existing forecasts so that stronger connections can be formed between EO-based information and flood impact: both smart, forecast-based decisions and simple, decision-based forecasts are needed. ${ }^{58}$ In this context, forecast tailoring means more than model calibration and validation, and includes how to present and interpret forecasts and their uncertainties for defining impact-based triggers. The aim is to allow access to forecast outputs in such a way that they can be applied and interpreted with greatest flexibility, and whenever possible, to curate forecast variables that have good predictability and high correlations with flood impacts in the particular region of interest.

For example, tailoring precipitation forecasts for a given region, could include testing different combinations of rainfall variables such as rainfall intensity and duration to determine, which are the most correlated with flood impact. ${ }^{20,41}$ If a streamflow or river height forecast is available, tailoring could mean linking flood extents or depths associated with certain streamflows or river heights, as discussed in Sec. 3.2, and overlaying those extents/depths with exposure and vulnerability information to estimate potential impact. Tailoring could also mean respecting the limitations of EO and incorporating contextual local knowledge through household and community surveys. For example, if certain sections of the river are known to overflow their banks more often, this information can be used to interpret where potential impacts from a given streamflow are likely to occur and guide actions to reinforce levees or clear drainage canals. ${ }^{59}$

To reach an $\mathrm{FbA}$ audience, the $\mathrm{EO}$ and flood forecasting communities could change how they report and present flood forecast verifications and accuracy assessments, beyond those called for by many in the hydrology community (e.g., Ref. 34). Further improvements could involve codeveloping new and common performance metrics relevant to each early action and its required lead time, all of which could be disaggregated at local scales (e.g., How skilled is a flood forecast in identifying conditions that should trigger the distribution of water purification tablets in different communities across the program area?). ${ }^{60}$ To facilitate this, flood modelers could communicate their accuracy assessments for extreme events for individual gauges and over the full range of forecast lead times.

Results of an FbA program evaluation may also open opportunities for further tailoring. For instance, within one $\mathrm{FbA}$ program area, an evaluation may uncover disparities among community benefits of early actions intended to reduce flood costs or impacts. Such findings may orient efforts to further tailor forecasts and redefine triggers to capture differing impacts within a program area, similar to the approaches and challenges faced in defining unit areas or zones by 
the index insurance sector. ${ }^{61-64}$ In this scenario, the operational phase would need sufficient resources to take more locally specific actions. In another instance, an EO-informed evaluation may help assess the reach of the early action or intervention. For example, EO may show that a flood caused much wider impacts, but only a small section of the river was evacuated.

\subsection{Challenges Beyond the Forecast}

In approaching research on $\mathrm{FbA}$ through the lens of EOs, it is important to note that many of the challenges with translating forecasts into action are actually not related to the forecast itself. Certainly, work is needed in improving forecasts, understanding which forecasts to use, and tailoring them for specific applications so that it is easier for decision-makers to take action. However, much of the difficulty has to do with funding, political considerations, and coordination and information sharing across organizations-areas beyond the scope of the scientific community. ${ }^{59}$ Since taking action on a forecast requires multiple groups to come together, it is important that no one group work in isolation. Scientists working with EOs and forecasts must work together with those who will use their forecasts and become aware of the many difficulties they face, even if they are beyond the scientific scope.

Trust in forecast sources remains a challenge in designing and operating flood $\mathrm{FbA}$ programs. Global monitoring and forecast systems play an important role, especially in monitoring ungauged and transboundary basins and forecasting at longer lead times, but it is critical that the EO community contributes to strengthening national and regional flood early warning systems. Doing so will not only improve our understanding of the water cycle and how to produce impact-based forecasts, but it will also build trust and confidence in the local agencies responsible for risk reduction.

\subsection{Roadmap Moving Forward}

This paper identifies clear opportunities for EO science and data to inform different phases of the $\mathrm{FbA}$ life cycle. The below roadmap reflects on key thematic elements that can enable the opportunities identified, including collaboration and partnership, consideration of future EO missions, transparency and no-regrets measures, and the role of "boundary organizations" to facilitate communication, translation, and mediation across the current EO-FbA divide. Collectively, these provide greater recognition and support toward this collaborative vision and hope for success.

Groups within the applied EO community and the humanitarian community both aim to reduce flood impacts. Both must also gather evidence of their contributions to risk reduction. Collaboration on $\mathrm{FbA}$ would allow each community to support each other's scientific and humanitarian missions and in gathering evidence of individual and shared successes. By collaborating more deeply in the design and evaluation phases, the EO community can enhance the humanitarian community's ability to take effective early action to reduce flood losses. In turn, the humanitarian community can provide additional evidence from the field on the use and remaining limitations of EO science and technology.

The applied sciences community will share immediate joint successes with the humanitarian community by tailoring EO inputs that are most "ready" to serve needs of impact-based early action (Table 2). The EO inputs that we classified as less ready for FbA point to opportunities for additional fundamental and interdisciplinary research. The humanitarian community has posed challenges that can justify future research and applications of new satellite missions and is likely to provide evidence of societal benefit from such missions (e.g., Ref. 65). For instance, the NASA-Indian Space Research Organization-synthetic aperture radar mission will allow us to significantly augment EO-based historic flood catalogs that can be integrated into the $\mathrm{FbA}$ design phase. Additionally, the $\mathrm{FbA}$ and $\mathrm{EO}$ communities can investigate the potential for satellite altimetry measurements to complement triggers designed with in situ stream gauge data and streamflow forecasts, especially in ungauged basins. Collaborators may ask which flood early actions, and where could data products from the forthcoming Surface Water Ocean Topography (SWOT) satellite mission inform with its significantly greater coverage and ability to capture finer scale transboundary river height and streamflow monitoring data to complement existing flood EWS than offered by previous EO (Fig. 2). 


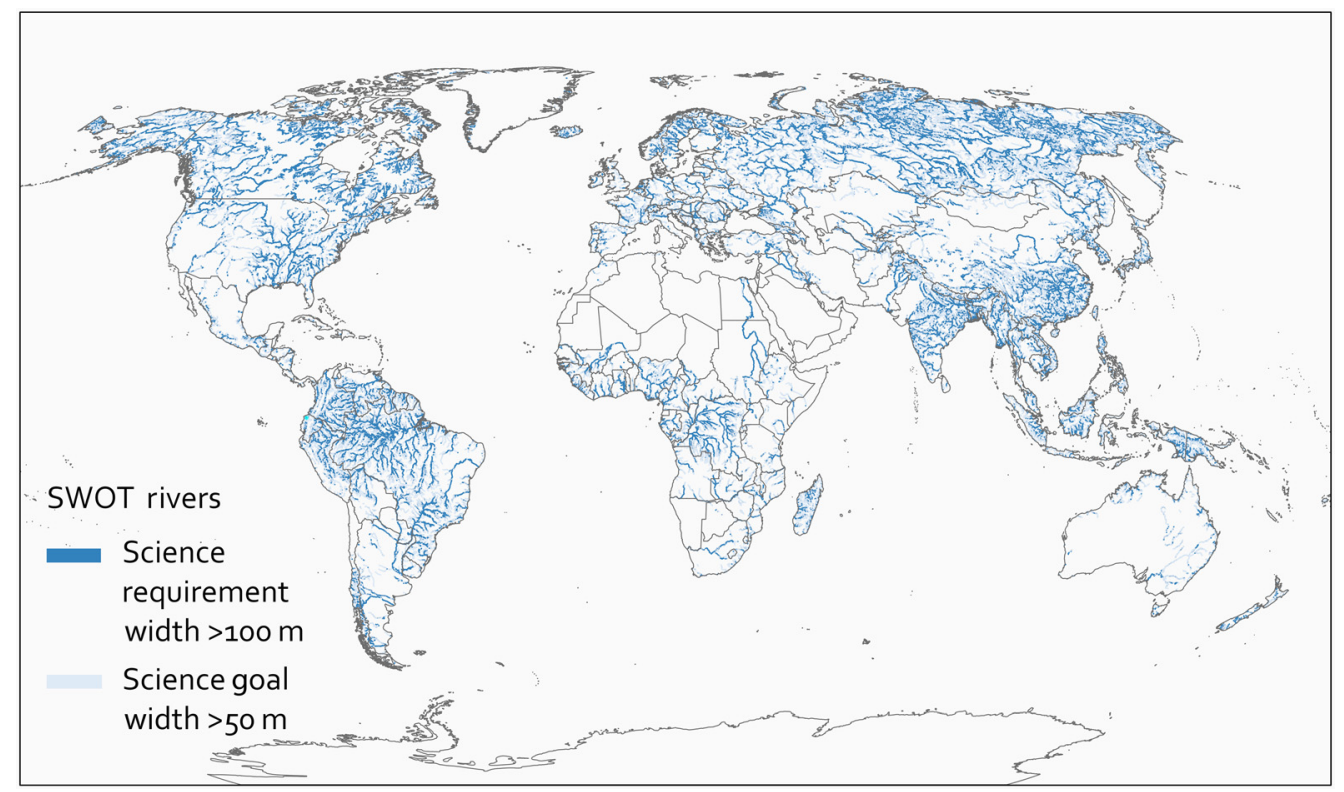

Fig. 2 SWOT will monitor significantly more rivers (derived from Ref. 66) than current and past satellite-based altimeters. The satellite mission is required to measure every river $>100-\mathrm{m}$ wide, and scientists aim to measure every river $>50-\mathrm{m}$ wide, ${ }^{67}$ offering much more data to inform different phases of flood FbA.

Joint success in flood risk reduction requires more open sharing of information from both sides. This could mean presenting the skill of EO-informed forecasts in different ways (e.g., per basin, how skill changes with lead time). Open sharing also means more documentation and transparency in early action protocols, particularly on the early warning inputs: the original model or forecast sources (and if available, a reference to a publication describing the forecast model setup), the thresholds with units for each unique impact-based trigger, the geographic area that each early action covers, and the lead time required for each action. As anticipatory or early action protocols aim to trigger action based on reducing impact, the scientific community would learn from more detailed justifications that describe how triggers have been linked with local and regional impact; in turn, this knowledge would position EO scientists to collaborate more meaningfully in determining the most appropriate monitoring or forecasting inputs to inform impactbased early warning and early action. In fact, impact-based triggers assume an understanding of vulnerability to floods, which is often highly uncertain. More significant collaborations between the physical flood forecasting communities and the vulnerability mapping communities would result in scientific discoveries and more rigorously designed impact-based triggers, however with increased collaboration, there is a need to increase identification of roles and responsibilities, as well as incentive structures, for each scientists, decision makers, and intermediaries. ${ }^{68,69}$

The early actions in Table 3 are only a few of the dozens of starting points for EO scientists and practitioners to collaborate with FbA designers, operators, and evaluators. Each early action should seed conversations about the readiness of EO to enhance existing inputs to reduce flood impacts. For each action, collaborators should discuss forecast lead time and uncertainty, the need or ability to design spatially disaggregated triggers, how each trigger for these actions is tied to impact, and more. The sample of early actions in Table 3 span lead times from general preparedness years in advance to months, weeks, days, and hours. The lead time column should orient EO scientists in considering the appropriateness of historic monitoring variables, seasonal forecasts, and near real-time forecasting variables, and the actions they can inform. Finally, the EO community should understand that some actions are no regrets such as awareness campaigns and general risk reduction actions. Other actions that affect livelihoods, such as evacuations, are highly regrettable if a false alarm occurs. We provide a more comprehensive table that can spark collaborative conversations toward realizing collective successes in flood impact reduction, in the appendix. 
Nauman et al.: Perspectives on flood forecast-based early action and opportunities...

Table 3 Example flood early actions (see full table in the appendix).

\begin{tabular}{llc}
\hline \hline Early actions & \multicolumn{1}{c}{ Lead time } & Reference \\
\hline $\begin{array}{l}\text { Work with communities to reduce risk through } \\
\text { concrete actions (e.g., reforestation and } \\
\text { reinforcement of houses) }\end{array}$ & $\begin{array}{l}\text { General preparedness } \\
\text { years in advance }\end{array}$ & 12 \\
$\begin{array}{l}\text { Build shelters; build latrines } \\
\begin{array}{l}\text { Support storage of seeds and food items; bag } \\
\text { vulnerable items and move storage facilities } \\
\text { to higher ground }\end{array}\end{array}$ & Three months & 37 \\
$\begin{array}{l}\text { Preposition buckets and chlorine tablets; } \\
\text { preposition hygiene kits }\end{array}$ & 5,37 \\
$\begin{array}{l}\text { Distribute biodegradable trash bags, jerry cans, } \\
\text { soap, buckets, chlorine tablets, and hygiene } \\
\text { kits to vulnerable households }\end{array}$ & one month to one week & 5,37 \\
\begin{tabular}{l} 
Evacuate \\
\hline \hline
\end{tabular} & & $5,11,37$ \\
\hline
\end{tabular}

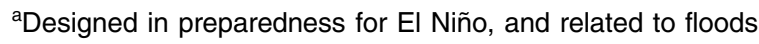

The international applied sciences community and the humanitarian community often target the same users and beneficiaries but from different orientations and vernaculars. Applied EO scientists often work with hydro-meteorological agencies to develop capacity to characterize flood hazards and their impacts. Likewise, humanitarian organizations implementing forecast-based early action programs rely on the same hydrometeorological agencies for actionable forecasts. Meaningful collaboration requires boundary organizations (referring both to persons and to organizations) in both camps who can empathize and understand others' unique challenges and opportunities, and who can communicate each other's goals, metrics, and challenges. Since the task goes beyond mere translation (i.e., tasking a person with replacing words from one language to another), we embrace the term "boundary organization": persons and organizational arrangements with functions that enable interactions across the EO-FbA boundary, including communication, translation, and mediation. Building on lessons outlined by Cash,${ }^{70}$ boundary organizations can act as intermediaries between the arenas of science and decisions, with specialized roles within relevant organizations for managing the boundary; clear lines of responsibility and accountability to distinct social arenas on opposite sides of the boundary; and a forum in which information can be co-produced by actors from different sides of the boundary. Boundary organizations play key roles in connecting early action challenges to tailored information, helping them move from data to decisions. Program managers must value boundary organizations and understand their struggles when faced with conflicting institutional cultures and disparate metrics of success. New performance indicators should celebrate the roles and unique capabilities that boundary organizations develop to achieve more together. In addition to the typical science metrics of papers published and research dollars generated, new applied science indicators could look to the development and humanitarian sector for new performance metrics. For instance, the performance of scientists working on $\mathrm{FbA}$ could be measured by number of programs supported for early warning/early action, number of non-scientists engaged or trained, service on early action protocol development committees, number of value-added EO products integrated into early action and risk reduction in any phase of $\mathrm{FbA}$, or testimonials from humanitarian organizations, among others.

\section{Conclusions}

As FbA continues to gain momentum and EO science advances, new ways to connect these communities will emerge, not only for anticipating and addressing flood impacts as discussed here, but for other shocks triggered by events as diverse as droughts, El Niño, heat waves, cyclones, volcanic eruptions, cold waves, forest fires, and others. Future work could consider how the EO community can best serve humanitarian $\mathrm{FbA}$ in these other areas as well. The EO community 
should see great opportunities to advance its fundamental science and applications in response to the FbA community's challenge to design impact-based triggers. Flood early warning systems are still many years away from producing forecasts of impact (advances are underway, e.g., Refs. 71 and 72), but this should not discourage the design of impact-based triggers for early action today. There is an immediate opportunity to collaborate in the $\mathrm{FbA}$ design phase so that the more readily available flood variables such as precipitation and streamflow are tied to on-theground impact. In the longer term, research and development can help to realize the value for $\mathrm{FbA}$ of the intermediate to complex variables such as extent and exposure. To best serve the needs of the humanitarian community, EO scientists can work to tailor their forecasts, understand the challenges beyond the scientific scope, and share information as clearly and openly as possible. As EO scientists and humanitarians work together, boundary organizations that can engage with the two communities will play key roles in facilitating the conversations needed to help turn science into action and ultimately reduce flood impacts.

\section{Appendix}

Table 4 expands on Table 3. It provides examples of flood early actions that can be used to seed discussions between collaborating EO scientists and practitioners and FbA designers, operators, and evaluators.

Table 4 Example flood early actions.

\begin{tabular}{|c|c|c|c|c|}
\hline Early action & Reference & Hazards & Country & Lead time \\
\hline $\begin{array}{l}\text { Train volunteers from Red Cross } \\
\text { branches }\end{array}$ & 37 & $\begin{array}{l}\text { Floods and } \\
\text { El Niño }\end{array}$ & Peru & $\begin{array}{l}\text { Years/general } \\
\text { preparedness } \\
\text { at the beginning } \\
\text { of the season }\end{array}$ \\
\hline $\begin{array}{l}\text { Conduct vulnerability and capacity } \\
\text { assessments }\end{array}$ & 37 & $\begin{array}{l}\text { Floods and } \\
\text { El Niño }\end{array}$ & Peru & $\begin{array}{l}\text { Years/general } \\
\text { preparedness } \\
\text { at the beginning } \\
\text { of the season }\end{array}$ \\
\hline Create community risk maps & 37 & Floods & Peru & $\begin{array}{l}\text { Years/general } \\
\text { preparedness } \\
\text { at the beginning } \\
\text { of the season }\end{array}$ \\
\hline $\begin{array}{l}\text { Key actors confirm standard } \\
\text { operating procedures }\end{array}$ & 37 & $\begin{array}{l}\text { Floods and } \\
\text { El Niño }\end{array}$ & Peru & $\begin{array}{l}\text { Years/general } \\
\text { preparedness } \\
\text { at the beginning } \\
\text { of the season }\end{array}$ \\
\hline $\begin{array}{l}\text { Continually update risk maps and } \\
\text { identify changing vulnerable groups }\end{array}$ & 12 & Floods & - & Years \\
\hline Recruit additional volunteers & 12 & Floods & - & Years \\
\hline Establish new areas of work & 12 & Floods & - & Years \\
\hline $\begin{array}{l}\text { Work with communities to reduce } \\
\text { risk through concrete actions } \\
\text { (e.g., reforestation and } \\
\text { reinforcement of houses) }\end{array}$ & 12 & Floods & - & Years \\
\hline Provide drinking water for families & 5 & El Niño & Peru & Seasonal \\
\hline $\begin{array}{l}\text { Assist families in healthcare; raise } \\
\text { awareness on water and hygiene }\end{array}$ & 5 & El Niño & Peru & Seasonal \\
\hline $\begin{array}{l}\text { Raise awareness with families on } \\
\text { hygiene and community health }\end{array}$ & 5 and 37 & $\begin{array}{l}\text { Floods and } \\
\text { El Niño }\end{array}$ & Peru & $\begin{array}{l}\text { Seasonal to } \\
\text { three months }\end{array}$ \\
\hline
\end{tabular}


Nauman et al.: Perspectives on flood forecast-based early action and opportunities...

Table 4 (Continued).

\begin{tabular}{|c|c|c|c|c|}
\hline Early action & Reference & Hazards & Country & Lead time \\
\hline $\begin{array}{l}\text { Establish early warning committees, } \\
\text { and equip and train community brigades }\end{array}$ & 5 and 37 & $\begin{array}{l}\text { Floods and } \\
\text { El Niño }\end{array}$ & Peru & $\begin{array}{l}\text { Seasonal to } \\
\text { three months }\end{array}$ \\
\hline Support storage of seeds and food items & 5 and 37 & El Niño & Peru & $\begin{array}{l}\text { Seasonal to } \\
\text { three months }\end{array}$ \\
\hline $\begin{array}{l}\text { Strengthen and protect homes at } \\
\text { risk of collapse for families }\end{array}$ & 5 and 37 & El Niño & Peru & $\begin{array}{l}\text { Seasonal to } \\
\text { one month }\end{array}$ \\
\hline Build shelters & 37 & El Niño & Peru & Three months \\
\hline Revisit contingency plans & 12 & Floods & - & Months \\
\hline Replenish stocks & 12 & Floods & - & Months \\
\hline $\begin{array}{l}\text { Inform communities about enhanced } \\
\text { risk and what to do if the risk materializes } \\
\text { (e.g., clear drains) }\end{array}$ & 12 & Floods & - & Months \\
\hline Active chlorine production installations & 37 & Floods & Peru & One month \\
\hline Distribute first aid kits & 37 & $\begin{array}{l}\text { Floods and } \\
\text { El Niño }\end{array}$ & Peru & Lead time \\
\hline $\begin{array}{l}\text { Provide communities with temporary } \\
\text { housing for families }\end{array}$ & 5 & El Niño & Peru & Lead time \\
\hline $\begin{array}{l}\text { Install water collection system at } \\
\text { critical points }\end{array}$ & 37 & Floods & Peru & Lead time \\
\hline $\begin{array}{l}\text { Build temporary platforms for water } \\
\text { bladders (in case of forecast } \\
\text { of high impact weather) }\end{array}$ & 37 & Floods & Peru & Lead time \\
\hline Preposition hygiene kits & 37 & El Niño & Peru & Lead time \\
\hline Fumigate communities & 37 & El Niño & Peru & Lead time \\
\hline Preposition buckets and chlorine tablets & 5,37 & El Niño & Peru & $\begin{array}{l}\text { One month to } \\
\text { One week }\end{array}$ \\
\hline Alert volunteers and communities & 12 & Floods & - & Weeks \\
\hline $\begin{array}{l}\text { Meet with other response agencies } \\
\text { to enable better coordination }\end{array}$ & 12 & Floods & - & Weeks \\
\hline Closely monitor rainfall forecasts & 12 & Floods & - & Weeks \\
\hline $\begin{array}{l}\text { Bag vulnerable items and move storage } \\
\text { facilities to higher ground }\end{array}$ & 11 & Floods & Uganda & $\begin{array}{l}\text { Two to one } \\
\text { weeks }\end{array}$ \\
\hline Distribute biodegradable trash bags & 37 & Floods & Peru & Nine days \\
\hline Coordinate water distribution & 37 & Floods & Peru & Nine days \\
\hline $\begin{array}{l}\text { Distribute buckets, chlorine tablets, } \\
\text { and hygiene kits }\end{array}$ & 5 and 37 & $\begin{array}{l}\text { Floods and } \\
\text { El Niño }\end{array}$ & Peru & $\begin{array}{l}\text { Nine to seven } \\
\text { days }\end{array}$ \\
\hline $\begin{array}{l}\text { Install water reservoirs and temporary } \\
\text { water tanks }\end{array}$ & 5 & El Niño & Peru & One week \\
\hline Early evacuation & 5 & El Niño & Peru & One week \\
\hline Distribute jerry cans to vulnerable households & 11 & Floods & Uganda & One week \\
\hline
\end{tabular}


Table 4 (Continued).

\begin{tabular}{|c|c|c|c|c|}
\hline Early action & Reference & Hazards & Country & Lead time \\
\hline $\begin{array}{l}\text { Distribute soap and a } 30 \text {-day supply } \\
\text { of chlorine tablets to vulnerable households }\end{array}$ & 11 & Floods & Uganda & One week \\
\hline Dig trenches around homes to divert water & 11 & Floods & Uganda & One week \\
\hline Prepare for evacuation & 12 & Floods & - & Days \\
\hline Mobilize volunteers & 12 & Floods & - & Days \\
\hline $\begin{array}{l}\text { Get warnings and instructions out to } \\
\text { communities at risk }\end{array}$ & 12 & Floods & - & Lead time \\
\hline Storm proof houses (cyclone/hurricane/typhoon) & 12 & Cyclone & - & Lead time \\
\hline $\begin{array}{l}\text { Check emergency kits for batteries, torch, food } \\
\text { supplies, and radio (cyclone/hurricane/typhoon) }\end{array}$ & 12 & Cyclone & - & Lead time \\
\hline $\begin{array}{l}\text { Inform brigades and community leaders } \\
\text { about evacuation alert }\end{array}$ & 37 & Floods & Peru & Two days \\
\hline Evacuate & 12 & $\begin{array}{l}\text { Floods and } \\
\text { cyclone }\end{array}$ & - & Days to hours \\
\hline
\end{tabular}

\section{Disclosures}

The authors declare that they have no conflicts of interest regarding the publication of this paper.

\section{Acknowledgments}

Funding for this research was provided by the National Aeronautics and Space Administration (NASA) through SERVIR via NASA Cooperative Agreement No. NNM11AA01A. SERVIR is a joint program led by the US Agency for International Development (USAID) and NASA. This research was also supported by the UK Natural Environment Research Council and Department for International Development Science for Humanitarian Emergencies and Resilience (SHEAR) Program. This research was also supported by NASA Disasters Program through grant No. 80NSSC18K0342, and the Columbia University World Project ACToday. The idea for this paper was conceived after a workshop convened with support from the NASA Earth Applied Sciences Program including David Green and Nancy Searby of the Disasters Program and Capacity Building Program, respectively; the Red Cross Red Crescent Climate Centre; and Columbia University's International Research Institute for Climate and Society (IRI). Special thanks to Kara Siahaan for her help obtaining FbA location information and to Denis Macharia, Faith Mitheu, James Wanjohi and Calvince Wara from the Regional Centre for Mapping of Resources for Development for inspiration and insight.

\section{References}

1. A. T. Jeyaseelan, "Droughts and floods assessment and monitoring using remote sensing and GIS," in Satellite Remote Sens. and GIS Appl. Agric. Meteorol., pp. 291-313 (2003).

2. United Nations Office of Disaster Risk Reduction, "Hyogo framework for action 20052015: building the resilience of nations and communities to disasters," https://www .refworld.org/docid/42b98a704.html (2005).

3. United Nations Office of Disaster Risk Reduction, "Sendai framework for disaster risk reduction 2015-2030," https://www.undrr.org/publication/sendai-framework-disaster-riskreduction-2015-2030 (2015). 
4. United Nations Framework Convention on Climate Change Adaptation Committee, United Nations Framework Convention on Climate Change Secretariat, and Green Climate Fund Secretariat, "Technical meeting on adaptation (TEM-A)," 2019, https://unfccc.int/sites/ default/files/resource/20190411_songdo.pdf.

5. E. Wilkinson, "Forecasting hazards, averting disasters implementing forecast-based early action at scale," 2018, https://www.odi.org/sites/odi.org.uk/files/resource-documents/ 12104.pdf.

6. J. Kellett and A. Caravani, "Financing disaster risk reduction: a 20 year story of international aid," 2013, https://www.odi.org/sites/odi.org.uk/files/odi-assets/publications-opinion-files/ 8574.pdf.

7. R. Mechler, "Cost-benefit analysis of natural disaster risk management in developing countries," 2005, http://maail1.mekonginfo.org/assets/midocs/0003131-environment-costbenefit-analysis-of-natural-disaster-risk-management-in-developing-countries-manual.pdf.

8. S. Hallegatte, "A cost effective solution to reduce disaster losses in developing countries and evacuation," World Bank Policy Research Working Paper. World Bank, Washington DC (United States), 2012, https://documents.worldbank.org/en/publication/documents-reports/ documentdetail/190261468181486694/a-cost-effective-solution-to-reduce-disaster-losses-indeveloping-countries-hydro-meteorological-services-early-warning-and-evacuation.

9. World Food Programme, "Forecast-based financing in Nepal, a return on investment study," 2019, https://docs.wfp.org/api/documents/WFP-0000108408/download/?_ga=2.217085206 $.1293190927 .1596650172-1316650806.1594727194$.

10. A. Rüth et al., "Closing The Gap: reconciling short-term disaster response with long-term risk reduction with 'forecast-based financing' (FBF)," 2016, https://www.drk.de/fileadmin/ user_upload/Closing_the_gap_Fbf_policy_paper_GRC.pdf.

11. E. Coughlan de Perez et al., "Action-based flood forecasting for triggering humanitarian action," Hydrol. Earth Syst. Sci. 20(9), 3549-3560 (2016).

12. International Federation of Red Cross Red Crescent Societies, "Early warning > early action," 2008, http://www.ifrc.org/Global/Publications/disasters/ew-ea-2008.pdf.

13. E. Stephens, "Forecast-based action," 2015, http://www.climatecentre.org/downloads/files/ Stephens\%20et\%20al.\%20Forecast-based\%20Action\%20SHEAR\%20Final\%20Report.pdf.

14. E. Coughlan de Perez, "Forecast-based financing: an approach for catalyzing humanitarian action based on extreme weather and climate forecasts," Nat. Hazards Earth Syst. Sci. 15(4), 895-904 (2015).

15. Red Cross Red Crescent Climate Centre et al., "FbF practitioners manual," 2020, https:// manual.forecast-based-financing.org/.

16. International Federation of the Red Cross and Red Crescent Societies and Early Action Task Force, "Countries implementing early action" (2019).

17. International Federation of Red Cross and Red Crescent Societies, "Forecast-based action (FbA) by the DREF," 2020, https://media.ifrc.org/ifrc/fba/ (accessed 6 August 2020).

18. L. Alfieri, "Operational early warning systems for water-related hazards in Europe," Environ. Sci. Policy 21, 35-49 (2012).

19. World Meteorological Organization, "WMO guidelines on multi-hazard impact-based forecast and warning services," 2015, https://www.wmo.int/pages/prog/www/DPFS/ Meetings/ET-OWFPS_Montreal2016/documents/WMOGuidelinesonMulti-hazardImpactbasedForecastandWarningServices.pdf.

20. E. Coughlan de Perez et al., "Should seasonal rainfall forecasts be used for flood preparedness?” Hydrol. Earth Syst. Sci. 21(9), 4517-4524 (2017).

21. International Federation of Red Cross Red Crescent Societies, Red Cross Red Crescent Climate Centre, The Netherlands Red Cross, and German Red Cross, "Menu of triggers for forecast-based financing: step-by-step approach to designing trigger options," 2016, http://www.climatecentre.org/downloads/files/04_Menu_of_Triggers_For_Forecast_Based_ Financing.pdf.

22. A. Lopez, "Bridging forecast verification and humanitarian decisions: a valuation approach for setting up action-oriented early warnings," Weather Clim. Extremes 27, 100167 (2020).

23. J. C. Thompson, "Economic gains from scientific advances and operational improvements in meteorological prediction," J. Appl. Meteorol. 1(1), 13-17 (1962). 
24. R. W. Katz and A. H. Murphy, Economic Value of Weather and Climate Forecasts, Cambridge University Press, Cambridge (1997).

25. K. R. Mylne, "Decision-making from probability forecasts based on forecast value," Meteorol. Appl. 9(3), 307-315 (2002).

26. I. T. Jolliffe and D. B. Stephenson, Forecast Verification: A Practitioner's Guide in Atmospheric Science, Wiley, Oxford (2012).

27. P. C. Oddo and J. D. Bolten, "The value of near real-time Earth observations for improved flood disaster response," Front. Environ. Sci. 7, 127 (2019).

28. J. S. Hagen, "Development and evaluation of flood forecasting models for forecast-based financing using a novel model suitability matrix," Prog. Disaster Sci. 6, 100076 (2020).

29. B. P. Suarez, "Loss and damage in a changing climate: games for learning and dialogue that link HFA and UNFCCC," The Hague, The Netherlands.: Red Cross Red Crescent Climate Centre Working Paper Series, 2015, http://climatecentre.org/downloads/files/Case studies/ AW_RCCC_WP8_Suarez and al v3.pdf.

30. G. Schumann, "Progress in integration of remote sensing-derived flood extent and stage data and hydraulic models," Rev. Geophys. 47(4), RG4001 (2009).

31. G. K. Devi, B. P. Ganasri, and G. S. Dwarakish, "A review on hydrological models," Aquat. Procedia 4, 1001-1007 (2015).

32. World Meteorological Organization et al., "First steering committee meeting (SCM 1) Mekong river commission flash flood guidance (MRCFFG) system," Phnom Penh, Cambodia, 2016, https://www.wmo.int/pages/prog/hwrp/flood/ffgs/mrcffgs/documents/ Meeting-Report-MRCFFG-SCM1_Final.pdf.

33. J. Teng, "Flood inundation modelling: a review of methods, recent advances and uncertainty analysis," Environ. Modell. Software, 90, 201-216 (2017).

34. V. Maggioni and C. Massari, "On the performance of satellite precipitation products in riverine flood modeling: a review," J. Hydrol. 558, 214-224 (2018).

35. K. Sene, Flash Floods Forecasting and Warning, Springer, Dordrecht, Heidelberg, New York, London (2013).

36. International Federation of the Red Cross and Red Crescent Societies, "Bangladesh: floods, early action protocol summary," 2019, http://adore.ifrc.org/Download.aspx?FileId=288726.

37. C. R. Peruana et al., "Forecast-based financing," 2016, http://climatecentre.org/downloads/ files/NotaTecnicaFEN\%20-\%20Ingles\%2020set2016.pdf.

38. S. N. McClain, "Building risk-informed communities: applications of Earth observation data," in Earth Observation Applications and Global Policy Frameworks, A. Kavvada, D. Cripe, and L. Friedl, Eds., pp. 15-17, AGU and John Wiley \& Sons, Inc., Washington, DC (2020).

39. L. Alfieri, "GloFAS — global ensemble streamflow forecasting and flood early warning," Hydrol. Earth Syst. Sci. 17(3), 1161-1175 (2013).

40. NASA, "The application readiness level metric," 2013, https://www.nasa.gov/sites/default/ files/files/ExpandedARLDefinitions4813.pdf (accessed 7 August 2020).

41. K. Bischiniotis, "The influence of antecedent conditions on flood risk in sub-Saharan Africa," Nat. Hazards Earth Syst. Sci. 18(1), 271-285 (2018).

42. T. Roy, "Design and implementation of an operational multimodel multiproduct real-time probabilistic streamflow forecasting platform," J. Hydroinf. 19(6), 911-919 (2017).

43. A. Serrat-Capdevila, "Evaluation of the performance of three satellite precipitation products over Africa," Remote Sens. 8(10), 836 (2016).

44. E. Stephens, "Precipitation and floodiness," Geophys. Res. Lett. 42(23), 10316-10323 (2015).

45. R. Valdés-Pineda et al., "Bias correction of daily satellite-based rainfall estimates for hydrologic forecasting in the Upper Zambezi, Africa," Hydrol. Earth Syst. Sci. Discuss. (2016).

46. C. H. Chang, "A model-aided satellite-altimetry-based flood forecasting system for the Mekong River," Environ. Modell. Software 112, 112-127 (2019).

47. M. A. Okeowo, "Automated generation of lakes and reservoirs water elevation changes from satellite radar altimetry," IEEE J. Sel. Top. Appl. Earth Obs. Remote Sens. 10(8), 3465-3481 (2017). 
48. K. N. Markert, "AltEx: an open source web application and toolkit for accessing and exploring altimetry datasets," Environ. Modell. Software 117, 164-175 (2019).

49. T. C. Pagano, "Evaluation of Mekong River commission operational flood forecasts, 2000-2012," Hydrol. Earth Syst. Sci. 18(7), 2645-2656 (2014).

50. M. S. Rahman and L. Di, "The state of the art of spaceborne remote sensing in flood management," Nat. Hazards 85(2), 1223-1248 (2017).

51. C. H. Chang et al., "Hindcast and forecast of daily inundation extents using satellite SAR and altimetry data with rotated empirical orthogonal function analysis: case study in Tonle Sap Lake Floodplain,” Remote Sens. Environ. 241, 111732 (2020).

52. P. C. Oddo, A. Ahamed, and J. D. Bolten, "Socioeconomic impact evaluation for near real-time flood detection in the lower Mekong river basin," Hydrology 5(2), 23 (2018).

53. E. A. Bright, "LandScan 2017 high-resolution global population data set," (No. LandScan 2017 High-Resolution Global Population Da; 005854MLTPL00). Oak Ridge National Lab. (ORNL), Oak Ridge, TN (United States) (2018).

54. Facebook Connectivity Lab and Center for International Earth Science Information Network-CIESIN—Columbia University, "High resolution settlement layer (HRSL)," Source imagery for HRSL (C) 2016 DigitalGlobe, 2016, https://www.ciesin.columbia .edu/data/hrsl/ (accessed 27 February 2020).

55. Center for International Earth Science Information Network - CIESIN - Columbia University, "Gridded population of the world, version 4 (GPWv4): population density, revision 11," Palisades, NY: NASA Socioeconomic Data and Applications Center (SEDAC), 2018, https://doi.org/10.7927/H49C6VHW (accessed 27 February 2020).

56. M. Haklay and P. Weber, "Openstreetmap: user-generated street maps," IEEE Pervasive Comput. 7(4), 12-18 (2008).

57. Red Cross Red Crescent Climate Centre and German Red Cross, "Research road map forecast-based financing," 2019, https://www.climatecehttps://www.climatecentre. org/downloads/files/FbF\%20Research\%20Roadmap_April2019\%20\%283\%29.pdfntre.org/ downloads/files/FbFResearch Roadmap_April2019\%283\%29.pdf.

58. P. Suarez, "Linking climate knowledge and decisions: humanitarian challenges," Boston University The Frederick S. Pardee Center for the Study of the Longer-Range Future, 2009, http://www.bu.edu/pardee/files/2010/01/Pardee_Paper_7_Linking_Climate_Knowledge.pdf.

59. A. S. Tozier de la Poterie et al., "Understanding the use of 2015-2016 El Niño forecasts in shaping early humanitarian action in Eastern and Southern Africa," Int. J. Disaster Risk Reduct. 30, 81-94 (2018).

60. S. J. Mason, "Accessing and using climate data and information in fragile, data-poor states," 2015, https://www.iisd.org/publications/accessing-and-using-climate-data-and-informationfragile-data-poor-states.

61. O. Mahul, "Optimum area yield crop insurance," Am. J. Agric. Econ. 81(1), 75-82 (1999).

62. S. S. Raju and R. Chand, "Progress and problems in agricultural insurance," Econ. Political Weekly 42(21), 1905-1908 (2007).

63. S. Chantarat, "Designing index-based livestock insurance for managing asset risk in northern Kenya," J. Risk Insurance 80(1), 205-237 (2012).

64. M. Carter, "Index insurance for developing country agriculture: a reassessment," Апnи. Rev. Resour. Econ. 9, 421-438 (2017).

65. F. Hossain, "Engaging the user community for advancing societal applications of the Surface Water Ocean Topography mission," Bull. Am. Meteorol. Soc. 98(11), ES285-ES290 (2017).

66. G. H. Allen and T. M. Pavelsky, "Global extent of rivers and streams," Science 361(6402), 585-588 (2018).

67. S. Desai et al., "Surface water and ocean topography mission (SWOT) project science requirements document," Tech. Rep. JPL D-61923, National Aeronautics and Space Administration, Jet Propulsion Laboratory (2018).

68. A. Kruczkiewicz, "Review of climate services governance structures: case studies from Mali, Jamaica, and India," CCAFS Working Paper no. 236, CGIAR Research Program on Climate Change, Agriculture and Food Security (CCAFS), Wageningen, Netherlands (2018). 
69. A. Mohanty, "Exploring community resilience and early warning solution for flash floods, debris flow and landslides in conflict prone villages of Badakhshan, Afghanistan," Int. J. Disaster Risk Reduct. 33, 5-15 (2019).

70. D. W. Cash, "Knowledge systems for sustainable development," Proc. Natl. Acad. Sci. USA 100(14), 8086-8091 (2003).

71. F. Dottori, "An operational procedure for rapid flood risk assessment in Europe," Nat. Hazards Earth Syst. Sci. 17, 1111-1126 (2017).

72. L. Alfieri et al., "Advances in Pan-European flood hazard mapping," Hydrol. Process. 28(13), 4067-4077 (2014).

Claire Nauman is a recent graduate of the Earth system science master's program at the University of Alabama in Huntsville, where she served as the NASA/SERVIR Mekong Graduate Research Assistant. She received her BS degree in environmental engineering from the University of Notre Dame. She now works as a water resource engineer at SLR Consulting.

Eric Anderson is a research scientist with the University of Alabama in Huntsville Earth System Science Center, serving as the NASA/SERVIR associate chief scientist and Disasters Theme Lead. He holds an MS degree in Earth system science from the University of Alabama in Huntsville.

Erin Coughlan de Perez is the manager of the Climate Science Team at the Red Cross Red Crescent Climate Centre and an adjunct associate research scientist at Columbia University. She holds a $\mathrm{PhD}$ in climate science focused on disaster risk management.

Andrew Kruczkiewicz is a senior associate researcher at the Earth Institute, International Research Institute for Climate and Society, and faculty lecturer at the Columbia University Climate School. He is science advisor at the Red Cross Red Crescent Climate Centre. He holds an MA degree from Columbia University's Department of Earth and Environmental Sciences.

Shanna McClain serves a dual role as manager of the NASA Earth Sciences Division Global Partnerships Program and program advisor on risk reduction and resilience to NASA's Applied Sciences Program. She is a visiting scholar at the Environmental Law Institute. She received her $\mathrm{PhD}$ in environmental science and policy from Southern Illinois University.

Amanda Markert is a research scientist at the University of Alabama in Huntsville Earth System Science Center, serving as the NASA/SERVIR Mekong Regional Science Coordination Lead. She received her BS degree in meteorology from Virginia Tech and an MS degree in Earth system science from the University of Alabama in Huntsville.

Robert Griffin is an associate dean of the College of Science, an associate professor in the Department of Atmospheric and Earth Science, and a co-director for the Laboratory for Applied Science at the University of Alabama in Huntsville. He received his PhD in anthropology from Pennsylvania State University.

Pablo Suarez is the associate director for research and innovation at the Red Cross Red Crescent Climate Centre, as well as visiting research fellow at Boston University, and artist in residence at the National University of Singapore. He received his $\mathrm{PhD}$ in geography from Boston University. 